\title{
Renal Metabolism in Fetal and Newborn Sheep
}

\author{
HARRIET S. IWAMOTO, WILLIAM OH, AND ABRAHAM M. RUDOLPH \\ Cardiovascular Research Institute and the Departments of Pediatrics, Physiology, and Obstetrics, Gynecology, \\ and Reproductive Sciences, University of California, San Francisco, California 94143 and Department of \\ Pediatrics, Women and Infant's Hospital of Rhode Island and Brown University, Providence,
} Rhode Island 02908

\begin{abstract}
The substrate and oxygen uptake by some organs in intact developing animals has been described, however, the kidney has not been studied. To examine substrate and oxygen uptake by the kidney, we implanted polyvinyl catheters into the renal vein, descending aorta, inferior vena cava, and urinary bladder of 11 fetal sheep (120-125 days gestation) and eight newborn lambs (1 day postnatal). Four days after surgery, blood samples were obtained simultaneously from the renal vein, aorta, and inferior vena cava for determination of oxygen content and saturation, and glucose and lactate concentrations. Renal blood flow was determined by the radionuclide-labeled microsphere method in the fetal lambs and by measuring ${ }^{14} \mathrm{C}$-inulin clearance in the newborn lambs. The fetal and newborn kidneys consumed oxygen at rates of $123 \pm 16$ and $785 \pm 79 \mu \mathrm{mol} / \mathrm{min} / 100 \mathrm{~g}$ kidney weight (mean \pm SEM), respectively. The increase in oxygen consumption from the fetal to the newborn period was accompanied by an increase in oxygen extraction from $25-35 \%$, a large increase in oxygen delivery from $418 \pm 38$ to $2231 \pm 127$ $\mu \mathrm{mol} / \mathrm{min} / \mathbf{1 0 0} \mathrm{g}$, and marked increases in glomerular filtration rate and sodium reabsorption (measured in six additional fetal sheep and the eight newborn lambs). This suggests that the postnatal increase in renal tubular activity is associated with an increase in oxygen consumption. Lactate was taken up by both fetal and newborn kidneys, and in nine of the 11 fetuses and in four of the eight newborns, there was net glucose release from the kidney. (Pediatr Res 19: 641-644, 1985)
\end{abstract}

\section{Abbreviations}

A-V, arteriovenous

$\mathrm{VO}_{2}$, oxygen consumption

GFR, glomerular filtration rate

The transition from pre- to postnatal life is associated with a marked increase in oxygen consumption in the sheep (1). Most of this change is related to an increase in metabolism for maintenance of body temperature and ventilation. However, myocardial oxygen consumption also increases in response to the demands of increases in heart rate, arterial pressure, and peripheral vascular resistance $(2,3)$. After the placenta is removed from the circulation, the kidney must assume fluid regulatory and excretory functions. To achieve the increase in renal function, it might be expected that renal consumption of oxygen and substrates

Received November 14, 1984; accepted February 20, 1985.

Correspondence to Harriet S. Iwamoto, Ph.D., 1403-HSE, University of California, San Francisco, CA 94143.

Supported by Grants HD07232 and HD17618 from the US Public Health Service. increases after birth. Changes in the plasma concentration of oxygen and metabolic substrates, such as glucose and lactate, and in renal blood flow that occur after birth influence substrate delivery rates to the kidney and also may alter renal metabolism. To examine renal metabolism and oxygen consumption we have developed a method of sampling renal venous blood in chronically maintained preparations of sheep (4), and have used this method to measure arteriovenous concentration differences of oxygen and various potential substrates of renal metabolism in fetal and newborn sheep. In conjunction with measuring renal blood flow, we calculated the rates of renal uptake and release of these substances.

\section{MATERIALS AND METHODS}

Seventeen fetal sheep (119-133 days gestation) and eight newborn lambs (5-6 days old) were studied. For the fetal sheep study, pregnant ewes were fasted for 24-48 $\mathrm{h}$ prior to surgery. After local anesthesia with lidocaine $\mathrm{HCl}(2 \mathrm{ml}$ of $2 \%$ ), low epidural or spinal anesthesia was induced in the ewe with $4 \mathrm{ml}$ of $1 \%$ tetracaine hydrochloride (Pontocaine hydrochloride, Breon Laboratories, New York, NY). The ewes were placed in a supine position and polyvinyl catheters $(1.3 \mathrm{~mm}$ id, $2.3 \mathrm{~mm}$ od) were inserted into the left maternal dorsalis pedis artery and vein and passed centrally to lie in the inferior vena cava and descending aorta. Ten percent dextrose in $0.9 \%$ saline was infused intravenously and $50-100 \mathrm{mg}$ of ketamine hydrochloride (Vetalar, Parke-Davis, Morris Plains, NJ) was administered to the ewe during surgery every $15-20 \mathrm{~min}$.

Through a ventral midline abdominal incision, the pregnant horn of the uterus was palpated. The fetal hind portion was exteriorized through an $8-10 \mathrm{~cm}$ incision in the uterus. Under local anesthesia, polyvinyl catheters $(0.8 \mathrm{~mm}$ id, $1.2 \mathrm{~mm}$ od) were inserted into hindlimb arteries and veins and advanced to the descending aorta and inferior vena cava. A silicone-rubber catheter with multiple side-holes was inserted into the urinary bladder through a suprapubic incision as previously described (4). The fetal skin was incised 4-8 cm from the base of the 12th rib parallel with and anterior to the spine; through this incision the renal vein was exposed and a modified Teflon-polyvinyl catheter was inserted into the vein and secured with a 6-0 silk suture as described previously (4). All fetal incisions were sutured and the fetus was returned to the uterus. An additional polyvinyl catheter was inserted into the amniotic cavity. All fetal vascular catheters were filled with heparin sodium solution and sealed. The uterus and maternal abdomen were sutured in layers. Antibiotics $(600 \mathrm{mg}$ kanamycin and 1 million $U$ penicillin) were administered intravenously to the ewe and instilled into the amniotic cavity postoperatively and each day thereafter. At least 4 days elapsed between the surgery and experiment.

For the newborn lamb study, 1-day-old lambs were sedated with a subcutaneous injection of ketamine hydrochloride $(5 \mathrm{mg} /$ $\mathrm{kg}$ ). Additional ketamine was administered intravenously during 
surgery as needed. Using local anesthesia with $1 \%$ lidocaine $\mathrm{HCl}$, we placed polyvinyl catheters $(1.0 \mathrm{~mm}$ id, $1.8 \mathrm{~mm}$ od) into the dorsalis pedis arteries and veins and passed them centrally. As in the fetus, a silicone-rubber catheter was placed into the urinary bladder through a ventral abdominal incision. A Teflon-polyvinyl catheter was inserted into the left renal vein via a retroperitoneal incision. To prevent the renal venous catheter from being dislodged, the free end of the catheter was looped subcutaneously and the skin incision was sutured. After surgery was completed, antibiotics ( $1 \mathrm{~g}$ ampicillin and $10 \mathrm{mg} / \mathrm{kg}$ gentamycin) were administered intravenously. Studies were performed after at least 4 days of recovery.

The fetuses were studied while the ewe stood quietly in a study cage. Fetal pressures and heart rate were monitored continuously with Statham P23Db pressure transducers and a cardiotachometer triggered by the arterial pressure pulse, and recorded on a Beckman 8-channel Dynograph direct-writing recorder. Metabolic and renal function measurements were made in two groups of fetuses because the amount of blood that can be obtained from each fetus is limited. Metabolic measurements were made in 11 fetal sheep (123-133 days gestational age); blood samples were obtained simultaneously from the descending aorta and renal vein for determination of $\mathrm{pH}$, blood gases, oxygen content, glucose, and lactate concentrations. We determined renal blood flow by injecting $15-\mu \mathrm{m}$ diameter radionuclide-labeled microwere obtained simultaneously from the descending aorta and ${ }^{95} \mathrm{Nb},{ }^{54} \mathrm{Mn}$, or ${ }^{65} \mathrm{Zn}$ ) into the inferior vena cava while obtaining a reference sample from the descending aorta (5). Renal function was measured in six fetal sheep (119-126 days gestational age) as follows. A priming dose of ${ }^{14} \mathrm{C}$-inulin $(5-15 \mathrm{mCi} / \mathrm{mmol}$, Amersham Corp., Arlington Heights, IL) dissolved in 5\% dextrose in $0.20 \% \mathrm{NaCl}$ was injected $(10 \mu \mathrm{Ci} / \mathrm{kg})$ and an infusion $(0.1 \mu \mathrm{Ci} / \mathrm{min} / \mathrm{kg})$ was initiated at least $1 \mathrm{~h}$ prior to blood sampling. Urine was collected for four 20-min periods and blood was sampled at the midpoint of each urine collection period in order to determine $\mathrm{pH}$ and blood gases, $\mathrm{Na}$ concentration, and ${ }^{14} \mathrm{C}$-radioactivity in arterial plasma and urine. Metabolic and renal function measurements were made in the eight newborn lambs while they were quietly supported in a sling. ${ }^{14} \mathrm{C}$-inulin was administered and urine was collected as described for the fetal sheep study. At the midpoint of each urine collection period, blood samples were obtained simultaneously from the descending aorta and renal vein for the determination of $\mathrm{pH}$, blood gases, $\mathrm{O}_{2}$ content, ${ }^{14} \mathrm{C}$-radioactivity, glucose, lactate, $\beta$-hydroxybutyrate, and $\alpha$-amino nitrogen concentrations. We determined renal blood flow by measuring renal extraction of ${ }^{14} \mathrm{C}$-inulin and applying the Fick principle and Wolf's equation (6). Blood flow measured by this method is generally $10-15 \%$ higher than that measured by the microsphere method (7) (Iwamoto HS, unpublished observations).

Glucose concentrations in whole blood were determined on blood samples that were immediately chilled, precipitated in $\mathrm{Ba}(\mathrm{OH})_{2}$ and $\mathrm{ZnSO}_{4}$, and centrifuged. The extracts were stored at $-20^{\circ} \mathrm{C}$ until assay; we used a commercially available kit based on the glucose oxidase and peroxidase method (Sigma, St. Louis, $\mathrm{MO})$. Lactate and $\beta$-hydroxybutyrate concentrations in whole blood were determined on blood samples that were immediately chilled, precipitated with perchloric acid, and centrifuged. The extracts were stored at $-20^{\circ} \mathrm{C}$; we assayed lactic acid using lactate dehydrogenase (Sigma), and $\beta$-hydroxybutyrate using $\beta$ dehydrogenase after the extracts were neutralized (modification of Reference 8). $\alpha$-Amino nitrogen concentrations in plasma were determined by a method based on production of stable trinitrophenol derivatives (Barnes $\mathrm{N}$, Nishino $\mathrm{V}$, personal communication). $\mathrm{PO}_{2}, \mathrm{pH}$, and $\mathrm{PCO}_{2}$ were determined with a Corning Model 165 or 175 blood gas analyzer (Corning Medical, Medfield, MA). We estimated oxygen contents in fetal blood ( $\mathrm{ml} \mathrm{O}_{2} /$ dl blood) by multiplying the hemoglobin concentration by the fractional saturation of the blood and $1.35 \mathrm{ml} \mathrm{O}_{2} / \mathrm{g}$ hemoglobin. Oxygen contents in newborn blood were determined by use of a Lex- $\mathrm{O}_{2}$-Con (Lexington Instruments Corp., Waltham, MA). To obtain values with units of $\mathrm{mM}$, oxygen contents $\left(\mathrm{ml} \mathrm{O}_{2} / \mathrm{dl}\right)$ were divided by $22.4 \mathrm{ml} \mathrm{O} / \mathrm{mmol}$ and multiplied by 10 . Fetal values are an average of two determinations. In the newborns, renal blood flow and A-V oxygen content were measured during each of the four clearance periods. We calculated four values of oxygen consumption by multiplying each renal blood flow value by the simultaneously obtained A-V oxygen content. Thus, the numbers reported in Table 2 are the average of four values and may not equal average renal blood flow times average $\mathrm{A}-\mathrm{V}$ oxygen content (also reported in Table 2). Substrate fluxes were calculated in a similar manner. Plasma and urine sodium concentrations were determined by flame photometry (Instrumentation Laboratory, Inc., Lexington, MA; Beckman Instruments, Fullerton, CA). ${ }^{14} \mathrm{C}$ radioactivity was measured by liquid scintillation. GFR was calculated as urine cpm $\times$ urine flow rate divided by arterial $\mathrm{cpm}$. Renal sodium filtration rate was calculated as the product of arterial plasma sodium concentration and GFR. Sodium excretion rate was calculated as the product of urine sodium concentration and urine flow rate. Renal sodium reabsorption rate was calculated as filtration rate minus excretion rate. Statistical differences between fetal and newborn values were assessed by an unpaired $t$ test or Mann-Whitney $U$ test.

\section{RESULTS}

All animals included in these studies were in good health with total body and kidney weights, arterial $\mathrm{pH}$, and blood gas values within the expected range (Table 1).

Renal blood flow and arterial oxygen content were greater in newborn than in fetal lambs (Table 2). Oxygen delivery to the kidney, calculated as arterial oxygen content times renal blood flow, was $2221 \pm 204 \mu \mathrm{mol} / \mathrm{min} / 100 \mathrm{~g}$ in the newborns and 496 \pm 77 in the fetuses (significantly different values, $p<0.001$ ). In addition to the higher oxygen delivery rate to the newborn kidney, oxygen extraction by the newborn kidney was also greater (35 versus $25 \%$ for the newborn versus fetal sheep, $p<0.05$ ). Consequently, the amount of oxygen consumed by the newborn kidney was much greater than that consumed by the fetal kidney.

The GFR in newborn sheep was more than six times that in fetal sheep (Table 3). Sodium filtration rate was greater and sodium excretion rate was less in newborn sheep. In addition, the actual and fractional amount of sodium reabsorbed by the newborn kidney was significantly greater than that reabsorbed by the fetal kidney.

Arterial glucose concentrations were greater in the newborn than in the fetal sheep (Table 4). In nine of 11 fetuses and in four of eight newborn sheep arteriovenous concentration difference was negative for glucose across the kidney indicating that the kidney produced glucose. Arterial lactate concentrations in the fetuses $(1.42 \pm 0.12 \mathrm{mM})$ were significantly greater than in the newborns $(0.87 \pm 0.04 \mathrm{mM}, p<0.01)$ (Fig. 1). Arteriovenous difference for lactate was consistently positive across the fetal $(0.12 \pm 0.02 \mathrm{mM})$ and newborn $(0.06 \pm 0.08 \mathrm{mM})$ renal circulations indicating net lactate uptake. There was no net flux of $\alpha$ amino nitrogen, but there was net uptake of $\beta$-hydroxybutyrate by the newborn kidney (Fig. 2) at a rate $(19.6 \pm 2.8 \mu \mathrm{mol} / \mathrm{min} /$ $100 \mathrm{~g}$ ) which could account for $13 \pm 2 \%$ of the oxidative metabolic rate.

Table 1. Total body and kidney wt, and $\mathrm{pH}, \mathrm{PO}_{2}, \mathrm{PCO}_{2}$ of arterial blood in fetal and newborn sheep (mean \pm SEM)

\begin{tabular}{lcc}
\hline & Fetus & Newborn \\
\hline$n$ & 17 & 8 \\
Body wt (kg) & $2.90 \pm 0.12$ & $5.21 \pm 0.47^{*}$ \\
Kidney wt (g) & $28.8 \pm 1.30$ & $40.2 \pm 1.39^{*}$ \\
pH & $7.36 \pm 0.01$ & $7.34 \pm 0.01^{*}$ \\
$\mathrm{Po}_{2}$ (torr) & $21 \pm 0.5$ & $95 \pm 2.4^{*}$ \\
$\mathrm{PCO}_{2}$ (torr) & $52 \pm 1.0$ & $34 \pm 1.1^{*}$ \\
\hline
\end{tabular}

${ }^{*} p<0.05$, significantly different from fetal values. 
Table 2. Renal blood flow, oxygen content, and oxygen consumption in fetal and newborn sheep

\begin{tabular}{|c|c|c|c|c|c|c|}
\hline \multirow[b]{2}{*}{$n$} & \multicolumn{2}{|c|}{$\begin{array}{l}\text { Blood flow } \\
\text { (ml/min) }\end{array}$} & \multicolumn{2}{|c|}{$\begin{array}{c}\mathrm{O}_{2} \text { content } \\
\mathrm{mM}^{*}\end{array}$} & \multicolumn{2}{|c|}{$\begin{array}{c}\text { Oxygen } \\
\text { consumption } \\
(\mu \mathrm{mol} / \mathrm{min})\end{array}$} \\
\hline & & per $100 \mathrm{~g}$ & $\mathbf{A}$ & A-V & & per $100 \mathrm{~g}$ \\
\hline \multicolumn{7}{|l|}{ Fetus } \\
\hline I & 52.4 & 148 & 2.67 & 0.63 & 33.16 & 94 \\
\hline 2 & 35.0 & 131 & 3.40 & 0.60 & 21.02 & 79 \\
\hline 3 & 55.5 & 203 & 2.86 & 0.79 & 43.86 & 160 \\
\hline 4 & 44.7 & 163 & 3.16 & 0.76 & 33.94 & 124 \\
\hline 5 & 34.9 & 150 & 2.33 & 0.83 & 29.00 & 125 \\
\hline 6 & 45.7 & 192 & 2.79 & 0.59 & 26.99 & 113 \\
\hline 7 & 29.7 & 139 & 1.68 & 0.54 & 16.02 & 75 \\
\hline 8 & 46.9 & 135 & 3.13 & 0.68 & 31.9 & 92 \\
\hline 9 & 51.3 & 121 & 2.37 & 0.60 & 30.8 & 73 \\
\hline 10 & 81.4 & 356 & 3.23 & 0.68 & 55.3 & 242 \\
\hline 11 & 67.6 & 222 & 2.44 & 0.77 & 52.4 & 171 \\
\hline Mean & 49.55 & 178 & 2.73 & 0.68 & 34.04 & 123 \\
\hline SEM & 4.75 & 21 & 0.16 & 0.03 & 3.83 & 16 \\
\hline \multicolumn{7}{|l|}{ Newborn } \\
\hline 1 & 176 & 464 & 5.62 & 2.59 & 478 & 1265 \\
\hline 2 & 153 & 358 & 5.27 & 1.97 & 297 & 698 \\
\hline 3 & 183 & 408 & 6.04 & 1.45 & 274 & 612 \\
\hline 4 & 190 & 475 & 5.32 & 2.41 & 473 & 1181 \\
\hline 5 & 150 & 331 & 3.81 & 1.94 & 404 & 668 \\
\hline 6 & 112 & 278 & 6.18 & 1.36 & 154 & 384 \\
\hline 7 & 161 & 465 & 5.30 & 1.56 & 247 & 715 \\
\hline 8 & 161 & 448 & 6.34 & 1.70 & 272 & 755 \\
\hline Mean & $161 \dagger$ & $403 \dagger$ & $5.49 \dagger$ & $1.87 \dagger$ & $325 \dagger$ & $785 \dagger$ \\
\hline SEM & 9 & 28 & 0.301 & 0.168 & 44 & 111 \\
\hline
\end{tabular}

* $A$ is concentration in descending aorta; A-V is concentration difference between descending aorta and renal vein.

$\dagger p<0.001$, significantly different from fetal value.

Table 3. Sodium handling by fetal and newborn sheep kidneys (mean $\pm S E M)$

\begin{tabular}{lcc} 
& Fetus & Newborn \\
\hline$n$ & 6 & 8 \\
GFR $(\mathrm{ml} / \mathrm{min})$ & $2.43 \pm 0.11$ & $15.93 \pm 5.93^{*}$ \\
Filtration $(\mu \mathrm{Eq} / \mathrm{min})$ & $361 \pm 16$ & $2294 \pm 394^{*}$ \\
Reabsorption $(\mu \mathrm{Eq} / \mathrm{min})$ & $337 \pm 18$ & $2291 \pm 395^{*}$ \\
Excretion $(\mu \mathrm{Eq} / \mathrm{min})$ & $23 \pm 4$ & $3.5 \pm 1.2^{*}$ \\
Reabsorption $(\%)$ & $93.4 \pm 1.3$ & $99.8 \pm 0.1^{*}$ \\
\hline
\end{tabular}

* $p<0.005$, significantly different from fetal value.

\section{DISCUSSION}

Among the important changes that occur at birth are the removal of the placenta from the circulation and the assumption by the kidney of fluid regulatory and excretory functions. Renal blood flow increases from 3-4\% of combined ventricular output in fetal lambs (9) to 8-10\% of cardiac output in newborn lambs $(10,11)$. We have confirmed that the kidney of newborn lambs receives three to four times more blood flow than the fetal kidneys in relation to renal mass, and have shown that oxygen consumption by the newborn kidney increases markedly as compared with the fetal kidney.

We have determined that the rate of $\mathrm{VO}_{2}$ by the fetal sheep kidney at $123-133$ days gestation is $123 \pm 16 \mu \mathrm{mol} / \mathrm{min} / 100 \mathrm{~g}$. Assuming that the fetuses in this study consumed oxygen at a rate previously reported for fetal sheep (19), the kidneys account for $3-4 \%$ of total $\mathrm{VO}_{2}$. This rate is comparable with the $\mathrm{VO}_{2}$ of the fetal gastrointestinal tract reported by Edelstone and Holzman (12) but less than that of the fetal brain (13), heart (2), and liver (14). We also determined that the $\mathrm{VO}_{2}$ of the newborn
Table 4. Glucose concentration and flux in fetal and newborn sheep

\begin{tabular}{|c|c|c|c|c|}
\hline & \multicolumn{2}{|c|}{ Glucose $\mathrm{mM}^{*}$} & \multicolumn{2}{|c|}{$\begin{array}{l}\text { Glucose flux } \\
(\mu \mathrm{mol} / \mathrm{min})\end{array}$} \\
\hline & A & $A \cdot V$ & & per $100 \mathrm{~g}$ \\
\hline \multicolumn{5}{|l|}{ Fetus } \\
\hline 1 & 0.687 & 0.012 & 0.629 & 1.77 \\
\hline 2 & 1.249 & -0.105 & -3.68 & -13.76 \\
\hline 3 & 0.934 & -0.015 & -0.833 & -3.04 \\
\hline 4 & 0.968 & -0.029 & -1.30 & -4.73 \\
\hline 5 & 0.577 & -0.004 & -0.140 & -0.601 \\
\hline 6 & 1.415 & -0.041 & -1.88 & -7.86 \\
\hline 7 & 0.749 & -0.018 & -0.534 & -2.50 \\
\hline 8 & 0.938 & -0.017 & -0.797 & -2.30 \\
\hline 9 & 1.12 & 0.00 & 0.00 & 0.00 \\
\hline 10 & 0.898 & -0.014 & -1.139 & -4.984 \\
\hline 11 & 0.918 & -0.088 & -5.949 & -19.54 \\
\hline Mean & 0.950 & -0.029 & -1.420 & -5.231 \\
\hline SEM & 0.077 & 0.012 & 0.594 & 2.008 \\
\hline \multicolumn{5}{|c|}{ Newborn } \\
\hline 1 & 5.67 & 0.015 & 0.660 & 1.74 \\
\hline 2 & 5.75 & -0.058 & -6.50 & -15.15 \\
\hline 3 & 6.16 & -0.410 & -70.70 & -158 \\
\hline 4 & 7.84 & -0.400 & -150 & -376 \\
\hline 5 & 6.35 & -0.165 & -20.38 & -45 \\
\hline 6 & 4.92 & 0.101 & 8.87 & 22.3 \\
\hline 7 & 4.76 & 0.014 & 1.04 & 5.30 \\
\hline 8 & 6.56 & 0.111 & 17.12 & 47.61 \\
\hline Mean & $6.001 \uparrow$ & -0.099 & -27.5 & -64.7 \\
\hline SEM & 0.370 & 0.079 & 21.3 & 53 \\
\hline
\end{tabular}

${ }^{*} \mathrm{~A}$ is concentration in descending aorta; $\mathrm{A}-\mathrm{V}$ is concentration difference between descending aorta and renal vein. Glucose flux was calculated in a manner similar to oxygen consumption.

$\dagger p<0.001$, significantly different from fetal value.
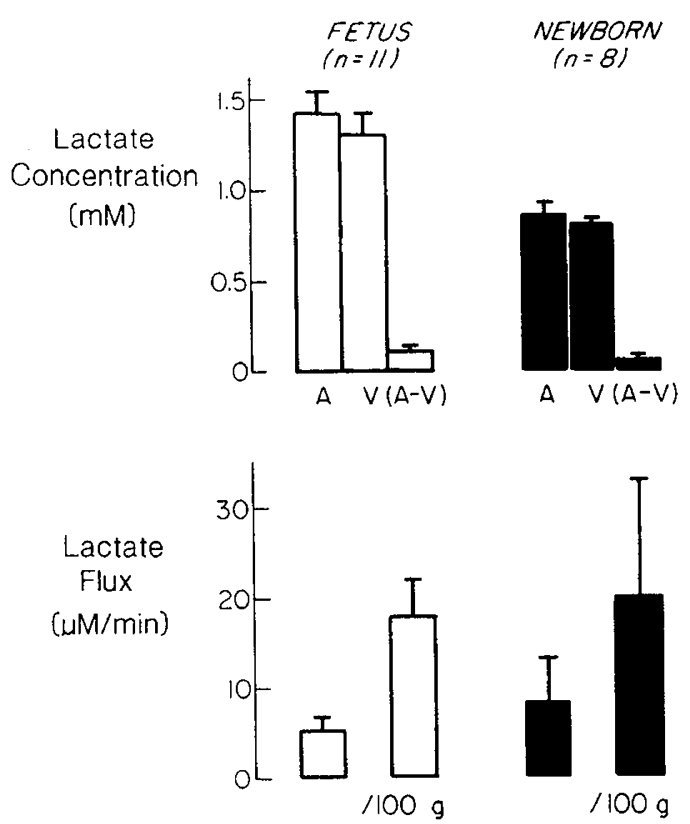

Fig. 1. Arterial, renal venous, and A-V concentrations of lactate in fetal and newborn sheep. Lactate flux was calculated in same manner as glucose flux. $(A-V)$ in newborns and $(A-V)$ and lactate flux in fetuses were significantly greater than zero, $(p<0.05)$.

kidney is approximately six times that of the fetal kidney and greater than that of the newborn heart (3), brain (15), and liver (16). The increase in renal $\mathrm{VO}_{2}$ after birth probably reflects the increase in renal function after birth. In addition, GFR and 


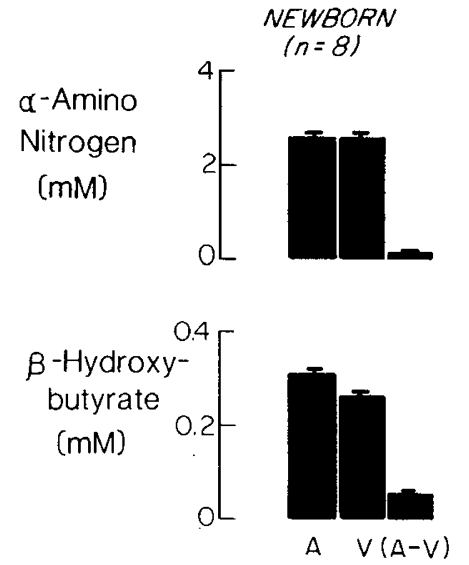

Fig. 2. Concentrations of $\alpha$-amino nitrogen and $\beta$-hydroxybutyrate in newborn lambs. $(A-V)$ for $\beta$-hydroxybutyrate was significantly greater than zero $(p<0.001)$, paired $t$ test.

sodium fitration rate are more than six times as great in newborn than in fetal sheep; our values are not significantly different from those previously reported $(17,18)$. The actual rate and fraction of the filtered sodium that was reabsorbed were also greater in newborn sheep. Since sodium reabsorption represents a major portion of renal tubular activity, this increase in sodium reabsorption requires an increase in metabolic activity, which probably accounts for the greater oxygen consumption rate by the newborn relative to the fetal kidney. A similar correlation between sodium reabsorption and oxygen consumption has been presented by Elinder and Aperia (7) in studies of neonatal rats.

The substrate-oxygen quotient is an expression of the proportion of total oxygen uptake that could be accounted for if a substrate is completely oxidized to $\mathrm{CO}_{2}$ and $\mathrm{H}_{2} \mathrm{O}$ (19). We calculated substrate-oxygen quotients and found that, in the newborn kidney, lactate uptake could account for $16 \pm 5 \%$ and $\beta$-hydroxybutyrate uptake could account for $13 \pm 2 \%$ of the oxidative metabolic requirement. In the fetal kidney, lactate uptake could account for $54 \pm 11 \%$ of the metabolic requirement. We were thus unable to account for the total substrate requirements of the developing kidney although we have not yet examined every potential substrate of metabolism. The kidneys may consume glucose derived from glycogen in the kidney, but this cannot be determined only by measuring net substrate fluxes across the renal vascular bed.

In nearly every fetus and in half the newborns studied A-V concentration difference for glucose was consistently positive across the renal circulation, indicating net release of glucose from the kidney. The glucose may have derived from glycogen breakdown or gluconeogenesis. The kidneys of developing lambs are known to store glycogen (20). The enzymes necessary to produce glucose from other substrates are present during the last trimester of gestation (21). Previous studies of total glucose turnover have not been able to demonstrate significant gluconeogenesis from either lactate or alanine (22); since the net glucose production by the kidney is a small percentage of total glucose turnover, it may not be possible to detect it. Renal gluconeogenesis has been reported to occur in the neonatal baboon and adult sheep (23, 24 ); in preliminary studies we have demonstrated renal gluconeogenesis from ${ }^{14} \mathrm{C}$-lactate in fetal lambs late in gestation (Gleason CA, Iwamoto HS, Rudolph AM, unpublished observations). In the present study, lactate taken up by the kidney could have been utilized directly or could have been directly converted to glucose and released or first deposited as glycogen then released as glucose, as has been shown to occur in adult rats $(25,26)$. The glucose released may be used by the rest of the body or by the kidney itself. The small net glucose produced by the kidney may not represent total gluconeogenesis because the kidney may utilize some of the glucose produced for its own metabolism. Further studies are required to confirm this notion.

\section{REFERENCES}

1. Dawes GS, Mott JC 1959 The increase in $\mathrm{O}_{2}$ consumption of the lamb after birth. J Physiol 146:295-315

2. Fisher DJ, Heymann MA, Rudolph AM 1980 Myocardial oxygen and carbohydrate consumption in fetal lambs in utero and in adult sheep. Am J Physiol 238:H399-H405

3. Fisher DJ, Heymann MA, Rudolph AM 1981 Myocardial consumption of oxygen and carbohydrates in newborn sheep. Pediatr Res 15:843-856

4. Iwamoto HS, Rudolph AM 1983 Chronic renal venous catheterization in fetal sheep. Am J Physiol 245:H524-H527

5. Baer RW, Payne BD, Verrier ED, Vlahakes GJ, Molodowitch D, Uhlig PN, Hoffman JIE 1984 Increased number of myocardial blood flow measurements with radionuclide-labeled microspheres. Am J Physiol 246:H418H434

6. Wolf AV 1941 Total renal blood flow at any urine flow or extraction fraction. Am J Physiol 133:496-497

7. Elinder G, Aperia A 1982 Renal oxygen consumption and sodium reabsorption during isotonic volume expansion in the developing rat. Pediatr Res 16:351353

8. Williamson DH, Mellanby J $1974 \mathrm{D}-(-)-3-$ Hydroxybutyrate. In: Bergmeyer HU (ed) Methods of Enzymatic Analysis, Vol 4. Academic Press, New York, pp 1836-1839

9. Rudolph AM, Heymann MA 1970 Circulatory changes during growth in the fetal lamb. Circ Res 26:289-299

10. Aperia A, Broberger O, Herin P, Joelsson I 1977 Renal hemodynamics in the perinatal period. A study in lambs. Acta Physiol Scand 99:261-269

11. Sidi D, Kuipers JRG, Teitel D, Heymann MA, Rudolph AM 1983 Developmental changes in oxygenation and circulatory responses to hypoxemia in lambs. Am J Physiol 245:H674-H682

12. Edelstone DI, Holzman IR 1982 Fetal intestinal oxygen consumption at various levels of oxygenation. Am J Physiol 242:H50-H54

13. Makowski EL, Schneider JM, Tsoulos NG, Colwill JR, Battaglia FC, Meschia G 1972 Cerebral blood flow, oxygen consumption, and glucose utilization of fetal lambs in utero. Am J Obstet Gynecol 114:292-303

14. Bristow J, Rudolph A, Itskovitz J, Barnes R 1983 Hepatic oxygen and glucose metabolism in the fetal lamb. Response to hypoxia. J Clin Invest 71:1-15

15. Gardiner RM 1980 Cerebral blood flow and oxidative metabolism during hypoxia and asphyxia in the new-born calf and lamb. J Physiol 305:357376

16. Edelstone DI, Holzman IR 1981 Oxygen consumption by the gastrointestinal tract and liver in conscious newborn lambs. Am J Physiol 240:G297-G304

17. Robillard JE, Sessions C, Kennedy RL, Hamel-Robillard L, Smith FG Jr 1977 Interrelationship between glomerular filtration rate and renal transport of sodium and chloride during fetal life. Am J Obstet Gynecol 128:727-734

18. Aperia A, Broberger O, Herin P 1974 Maturational changes in glomerular perfusion rate and glomerular filtration rate in lambs. Pediatr Res 8:758765

19. Battaglia FC, Meschia G 1978 Principal substrates of fetal metabolism. Physiol Rev 58:499-527

20. Shelley HJ 1961 Glycogen reserves and their changes at birth and in anoxia. Br Med J 17:137-143

21. Stevenson RE, Morriss FJ Jr, Adcock EW III, Howell RR 1976 Development of gluconeogenic enzymes in fetal sheep liver and kidney. Dev Biol 52:167172

22. Prior RL 1982 Gluconeogenesis in the ruminant fetus: evaluation of conflicting evidence from radiotracer and other experimental techniques. Fed Proc 41:117-122

23. Kaufman CF, Bergman EN 1971 Renal glucose, free fatty acid, and ketone body metabolism in the unanesthetized sheep. Am J Physiol 221:967-972

24. Levitsky LL, Paton JB, Fisher DE, Delannoy CW 1980 Arterial blood levels of energy substrates and evidence for renal glucose production in the baboon infant. Pediatr Res 14:926-932

25. Hems DA, Whitton PD, Taylor EA 1972 Glycogen synthesis in the perfused liver of the starved rat. Biochem J 129:529-538

26. Newgard CB, Hirsch LJ, Foster DW, McGarry JD 1983 Studies on the mechanism by which exogenous glucose is converted into liver glycogen in the rat. J Biol Chem 258:8046-8052 